Journal of Sustainable Development of Transport and Logistics

journal home page: https://jsdtl.sciview.net

Juyal, S., \& Yedla, S. (2020). Sustainability of transport system: Case study of Greater

Mumbai. Journal of Sustainable Development of Transport and Logistics, 5(2), 153-167.

doi:10.14254/jsdtl.2020.5-2.14.

ISSN 2520-2979

\title{
Sustainability of transport system: Case study of Greater Mumbai
}

\author{
Shikha Juyal *, Sudhakar Yedla ** \\ * Indira Gandhi Institute of Development Research, \\ NITI Aayog (erstwhile Planning Commission), Government of India, India \\ shikha.juyal@gmail.com \\ ** Indira Gandhi Institute of Development Research, \\ Goregaon (E), Mumbai 400065, India \\ sudhakar@igidr.ac.in
}

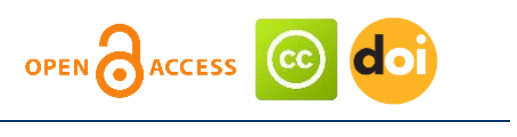

Article history:

Received: July 27, 2020

1st Revision: August 30, 2020

Accepted: November 07, 2020

DOI:

10.14254/jsdtl.2020.5-2.14

\begin{abstract}
Sustainable transport is about taking holistic approach by considering economic, society and environment along with the mobility and accessibility requirement of people. In case of Greater Mumbai, there is presence of inequity in provision of transport infrastructure and service. The first part of paper arrives at sustainability indicator by means of compounded economic, social \& demographic, land use and transport access indicators. The second part of paper measures the extent of sustainability in various wards of Greater Mumbai. It was important to study the extent of sustainability by measuring the gap between sustainability \& HDI indicator and sustainability \& transport access indicator. In terms of transport access, the gap between transport access indicator and sustainability indicator is present in most of the wards of Greater Mumbai. The overall result proves that there is urgent need to address the provision of transport access in most of the wards of Greater Mumbai. Purpose: The main purpose of this paper is to arrive at sustainability indicator and to measures the extent of sustainability in various wards of Greater Mumbai in transport. Methodology: The paper arrives at sustainability indicator by developing compounded economic, social and demographic, land use and transport access indicators. In order to calculate economic, social \& demographic, land-use and transport access indicator considered normalized value of each indicators derived from maximum point normalization across all wards. Finally equal weighted average of all indicators was taken to calculate the overall sustainability indicator. To measure the extent of sustainability in various wards of Greater Mumbai was done by comparing aggregate sustainable indicator with HDI indicator and transport access indicator. Result: The overall result proves that there is urgent need to address the provision of transport access in most of the wards of Greater Mumbai. The theoretical contribution: This paper
\end{abstract}

Corresponding author: Shikha Juyal

E-mail: shikha.juyal@gmail.com

This open access article is distributed under a Creative Commons Attribution (CC-BY) 4.0 license. 
arrives at sustainability indicator by compiling economic, social and demographic, land use and transport access indicators. Practical implications: This paper calculates ward level sustainability in Greater Mumbai and identifies the need to make provision of different transport infrastructure.

Keywords: sustainability, indicator, transport, Greater Mumbai.

\section{Introduction}

In Greater Mumbai, people do not have equal access to opportunities which is unfair. Investments do no justice to remove the mobility problems of poor, disadvantage \& vulnerable and services are unaffordable or inaccessible to certain section of society. A work by United Nations (2002) mentioned that a key to urban sustainability is that the three pillars of sustainability - environmental stewardship, social equity and economic efficiency are interdependent and should be mutually reinforcing (Nijkamp et. al., 2009). These are very important for proper functioning of transport system. Nijkamp (2009) in their work said that the urban form, transportation and interactions with communities are the central drivers of sustainability in cities. Understanding interactions between urban form, transportation and community is essential to interpret sustainability performance in terms of three pillars of sustainability.

Sustainable transport is about taking holistic approach by considering economic, society and environment along with the mobility and accessibility requirement of people. Many researchers have highlighted the need for sustainability in transport system. UN Habitat (2013) report explains social sustainability which is rooted in the principle of accessibility, wherein equality exists among all groups in terms of access to basic goods, services and activities and to enable people to participate in civic life. World Bank (1997) report on "poverty and transport" highlights this fact that transportation has important role to play in poverty reduction.

Despite the given facts, high investments are made on infrastructure such as roads and flyovers used by motorized transport or urban non-poor mostly as compared to subway, cycle track and footpaths and so on used by urban poor. There is increasing concerns to address the sustainability issues in urban transportation. Based on literature (Baker et al., 2005), in case of Mumbai, 66.9 percent poor use NMT, 16.1 percent use rail, 14.5 percent use public bus, 1.3 percent use $3 \mathrm{w}, 0$ percent use taxi, 0.7 percent use $2 \mathrm{w}$ and 0 percent own car and 0.2 percent use others car for work based trips. This shows that poor mostly use NMT followed by rail and public bus (almost 97.3 percent share) and for other modes proportion is very small. This shows that NMT is preferred mode for poor. The status of existing NMT infrastructure largely used by poor sections for the work trips shows that the subway, cycle track and footpaths are not even usable, occupied by hawkers and used for parking. The land used for walking is not integrated properly with other infrastructure facilities (such as sewerage systems, water supply systems, optical fiber placements, gas pipelines, and so on) in which work has always been in progress. This further creates problem for those who prefer to walk or cycle. As per UN Habitat (2013) report the access and mobility of the urban poor is constrained by city planning, socio-economic characteristics, transport facilities and the availability of services. The poor are increasingly concentrated on the periphery of urban areas and travel longer distances. Their report suggests that any deficiencies in public transport will have a greater impact on the urban poor. Lawson in their work (Lawson et al., 2013) mentions that non-motorized commuting such as walking and cycling to work is essential in attaining sustainability in urban mobility. The existing literature highlights the socio-economic condition of poor in Greater Mumbai in various wards. Mundu in their work (Mundu \& Bhagat, 2008) highlighted that most of the slum dwellers lack the basic necessities of life. The rapid growth of slums and squatter settlements has largely contributed to the social, economic and environmental problems in urban areas. The author mentions that in Greater Mumbai, out of 24 wards, 10 wards comprise more than 50 percent slum population. A large number of slum people are migrants; most of them belong to the lower socio economic group and come from different parts of the country. The majority of the slum population is concentrated in core areas of the city because they want to live nearer to their working places and contribute significantly to the economic activity of the city. Similarly, Abhyankar in their 
work (Abhyankar et al., 2013) pointed out that the MCGM has very high population density. There are six municipal wards in Mumbai namely, B (Sanhurst road), C (Marine line), H/E (Khar/Santacruz), K/E (Andheri east), $\mathrm{N}$ (Ghatkopar) and M/E (Chembur east) which have high exposure and low relief capacity.

The above literature shows why in case of Greater Mumbai, the sustainability of transport system is relevant. The literature explains the sustainable transport and need to measure the sustainability of transportation. The next section highlights some existing literature on how to measure sustainability in transport system.

\section{How to measure sustainability of transport system: Indicator Approach}

To measure sustainable transport system various researchers have used indicator approach. Miranda and Silva in their work (Miranda \& Silva, 2012) developed Index of Sustainable Urban Mobility (I_SUM) to assess the current mobility conditions of any city. The author considers nine domains with thirty seven themes covered which were further divided into eighty-seven indicators. The aggregation of index was done by weighted linear method. I_SUM was calculated for city of Curitiba. I_SUM considers accessibility, environmental aspects, social aspects, political aspects, transport infrastructure, nonmotorized modes, integrated planning, urban circulation traffic and urban transport indicators. Litman in their work (Litman \& Burwell, 2006) measures comprehensive sustainable transportation indicator. They have considered indicators like accessibility, transport diversity, affordability, facility costs, freight efficiency and planning for economic indicator; have considered safety, health \& fitness, community livability, equity, non-motorised transport planning \& citizen involvement for social indicator and have considered climate change emissions, other air pollution, noise pollution, water pollution, land use impacts, habitat protection \& resource efficiency for environmental indicator. Some indicators may overlap, some can be disaggregated, some indicators may be difficult to obtain or evaluate and some are ambiguous. Similarly, Nathan and Reddy in their work (Nathan, \& Reddy, 2011) proposed a Multi-view black-box (MVBB) framework for development of sustainable development indicators (SDIs). The author measures potential sustainable development indicator (SDI) for Mumbai transportation system. The 54 potential indicators of SDI were classified into three dimension of urban sustainability: economic efficiency (considered 19 indicators), social wellbeing (considered 18 indicators) and ecological acceptability (considered 17 indicators). Reddy and Balachandra in their study (Reddy \& Balachandra, 2013) investigates whether the present pattern of urban development in mega cities of Mumbai and Bangalore is sustainable considering economic, social and environmental dimensions. The author uses indicator approach and identifies gaps using gap analysis approach. The finding indicate that both Mumbai and Bangalore have large gaps to bridge with respect to economic sustainability where as they relatively better placed with respect to social and environmental sustainability. Tiwari and co-worker in their work (UNEP, 2011) present city level indicators. The author considered modal share, travel time, trip length \& affordability indicators to measure mobility and accessibility; considered infrastructure quality and land use indicators to measure infrastructure and land use; considered safety and security indicators to measure safety and security; considered emissions, depletion of land resources \& health hazards indicators to measure environmental impacts and considered investment, cost borne by operators \& fare policy indicators to measure economic (response indicators).

\section{Objective of the paper}

- To measure sustainability in Greater Mumbai: The research analysis will measure sustainability indicator compiled from compounded economic, social and demographic, land use and transport access indicators.

- To measure the extent of sustainability in various wards of Greater Mumbai: It was done by comparing aggregate sustainable indicator with HDI indicator and transport access indicator.

The ward-wise data was taken from Human Development Report (2009), MCGM Website and Preparatory Studies Report of draft development plan (2014-34) by MCGM. 


\section{Methodology}

The part one presents compounded indicators of sustainability among different wards.

\subsection{Measurement of sustainability indicator}

An appropriate sustainability indicator was developed based on below framework shown below in Figure 1. This was to done to understand the relative performance of wards on sustainability dimension in case of Greater Mumbai.

Figure 1: Flow chart for calculation of sustainability indicator

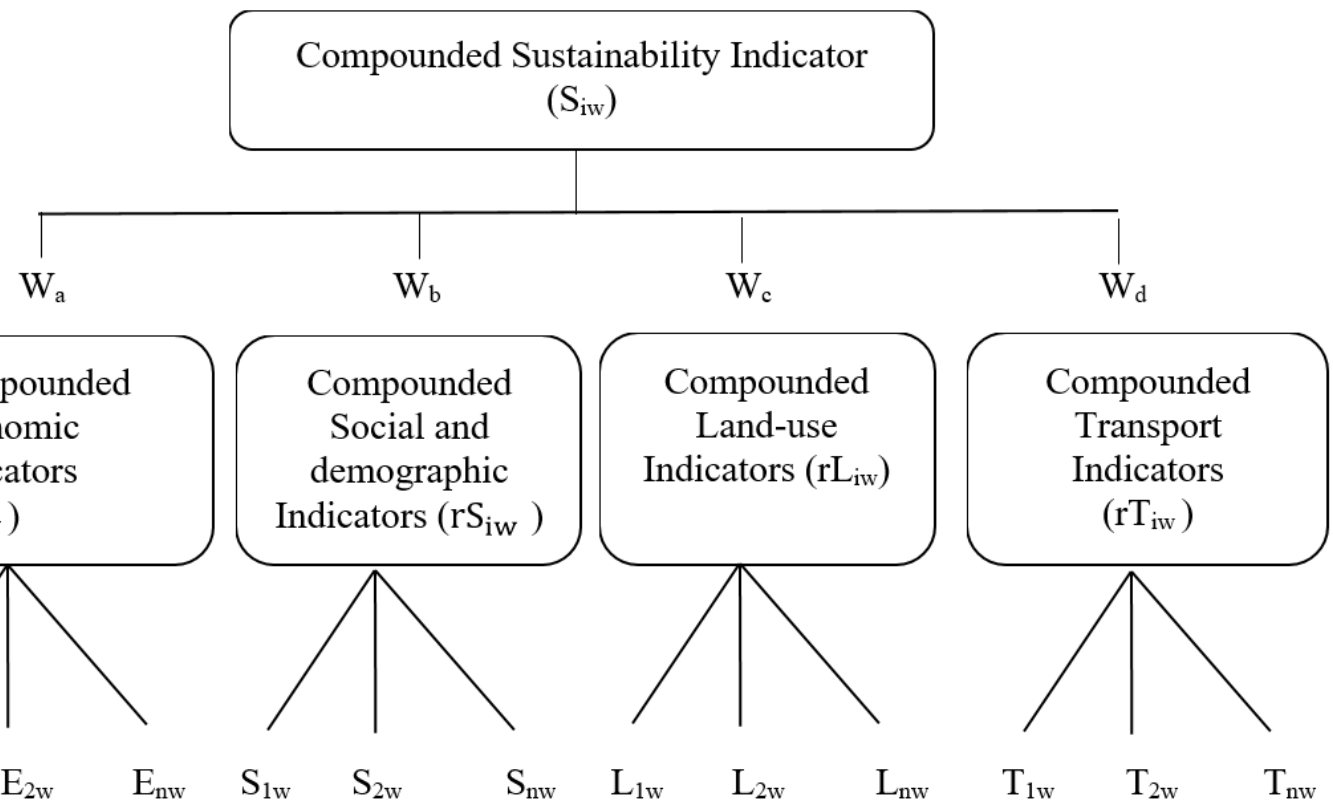

Note: $\mathrm{W}_{\mathrm{a}}, \mathrm{W}_{\mathrm{b} \ldots \ldots . . . .} \mathrm{W}_{\mathrm{n}}=$ Weights.

$\mathrm{E}_{1 \mathrm{w}} \ldots . . . \mathrm{E}_{\mathrm{nw}}=\quad$ Economic Indicators in different wards

$\mathrm{S}_{1 \mathrm{w}} \ldots \ldots . . . \mathrm{S}_{\mathrm{nw}}=$ Social and demographic Indicators in different wards

$\mathrm{L}_{1 \mathrm{w}} \ldots . . . . . . \mathrm{L}_{\mathrm{n}} \mathrm{w} \quad=$ Land-use Indicators in different wards

$\mathrm{T}_{1 \mathrm{w}} \ldots \ldots \ldots . . . \mathrm{T}_{\mathrm{nw}} \quad=$ Transport Indicators in different wards

$\mathrm{rE}_{\mathrm{iw}}=$ Relative compounded Economic Indicator in different wards

$\mathrm{rS}_{\mathrm{iw}}=$ Relative compounded Social and demographic Indicator in different wards.

$\mathrm{rL}_{\mathrm{iw}}=$ Relative compounded Land-use Indicator in different wards

$\mathrm{rT}_{\mathrm{iw}}=$ Relative compounded Transport Indicator in different wards

$S_{\mathrm{iw}}=$ Relative compounded Sustainability Indicator in different wards

\subsection{Measurement of compounded economic, social and demographic, land-use and transport access indicators}

In order to judge overall sustainability, this paper develops compounded indicators of economic, social and demographic, land-use and transport access (like road, rail, infrastructure and finance) indicators. The method considered to measure economic, social and demographic, transport and landuse indicators are as follows:

\section{Economic Indicator:}

$$
r E_{i w}=\left[\sum_{i=1}^{n} E_{i}\right] / n
$$


$\mathrm{rE}_{\mathrm{iw}}=$ Relative economic indicator for ward $(\mathrm{w})$. Range: $0<\mathrm{w}<\mathrm{m}$, Range: $0<\mathrm{rEi}_{\mathrm{w}}<1 \&$ for all measure 0 to 1 . Range: $0<\mathrm{Ei}<1$.

$\mathrm{n}=$ Total number of indicators

$E_{i}=\left(X-E I_{i}\right)$

where $\mathrm{X}=$ Ward with highest value of economic indicator and $\mathrm{EI}_{\mathrm{i}}=\mathrm{EI}_{1}, \mathrm{EI}_{2}$ $. . E I_{n}=$ Value of economic indicator in each ward. The economic indicator is derived from maximum point normalization across all wards.

\section{Social and Demographic Indicator:}

$$
r S_{i w}=\left[\sum_{i=1}^{n} S_{i}\right] / n
$$

$\&$ for all

$\mathrm{rS}_{\mathrm{iw}}=$ Relative socio-demographic indicator for ward (w).Range: $0<\mathrm{w}<\mathrm{m}$, Range: $0<\mathrm{rS}_{\mathrm{iw}}<1$

measure 0 to 1 . Range: $0<\mathrm{Si}<1$.

$\mathrm{N}=$ Total number of indicators

$\mathrm{S}_{\mathrm{i}}=\left(\mathrm{X}-\mathrm{SD}_{\mathrm{i}}\right)$

where $\mathrm{X}=$ Ward with highest value of socio-demographic indicator and $\mathrm{SD}_{\mathrm{i}}=\mathrm{SD}_{1}, \mathrm{SD}_{2}$ $\mathrm{SD}_{\mathrm{n}}=$ Value of socio-demographic indicator in each ward. The socio-demographic indicator is derived from maximum point normalization across all wards.

\section{Land Use Indicator:}

$$
r L_{i w}=\left[\sum_{i=1}^{n} L_{i}\right] / n
$$

$\mathrm{rL}_{\mathrm{iw}}=$ Relative land use indicator for ward $(\mathrm{w})$. Range: $0<\mathrm{w}<\mathrm{m}$, Range: $0<\mathrm{rL}_{\mathrm{iw}}<1 \&$ for measure 0 to 1 , Range: $0<\mathrm{Li}<1$.

$\mathrm{n}=$ Total number of indicators

$\mathrm{L}_{\mathrm{i}}=\left(\mathrm{X}-\mathrm{LU} \mathrm{U}_{\mathrm{i}}\right)$

where $\mathrm{X}=$ Ward with highest value of land use indicator and $\mathrm{LU}_{\mathrm{i}}=\mathrm{LU}_{1}, \mathrm{LU}_{2} \ldots \ldots \ldots \ldots . . . \mathrm{LU}_{\mathrm{n}}=$ Value of land use indicator in each ward. The land use indicator is derived from maximum point normalization across all wards.

\section{Transport Access Indicator:}

$$
r T_{i w}=\left[\sum_{i=1}^{n} T_{i}\right] / n
$$

$\mathrm{rT}_{\mathrm{iw}}=$ Relative Transport Access indicator for ward (w). Range: $0<\mathrm{w}<\mathrm{m}$, Range: $0<\mathrm{rT}_{\mathrm{iw}}<1 \&$ for all measure 0 to 1 , Range: $0<\mathrm{Ti}<1$.

$\mathrm{n}=$ Total number of indicators

$$
\mathrm{T}_{\mathrm{i}}=\left(\mathrm{X}-\mathrm{T}_{\mathrm{i}}\right)
$$

where $X=$ Ward with highest value of Transport Access indicator and $T_{i}=T_{1}, T_{2} \ldots \ldots \ldots \ldots T_{n}=$ Value of Transport Access indicator in each ward. The transport access indicator i derived from maximum point normalization across all wards.

In order to calculate economic, social \& demographic, land-use and transport access indicator considered normalized value of each indicators derived from maximum point normalization across all wards. This was done to explain the relative position across different wards of Greater Mumbai. The best ward was compared with other wards to finally arrive at best and worse off wards in Greater 
Mumbai. Finally equal weighted average of all indicators was taken to calculate the overall sustainability indicator.

What is Sustainability indicator?

$$
S_{i w}=w r E_{i w}+w r S_{i w}+w r L_{i w}+w r T_{i w} / n
$$

where Siw = Sustainability Indicator in different wards, wrEiw $=$ Weighted Relative Economic Indicator in different wards, wrSiw = Weighted Relative Social and demographic Indicator in different wards, wrLiw $=$ Weighted Relative Land use Indicator in different wards, wrTiw = Weighted Relative Transport Indicator in different wards and $\mathrm{n}=$ Total number of Indicators. The Sustainability indicator measures economic, social \& demographic, land use aspects and provision of transport in different wards of Greater Mumbai. The Table 1 below shows Indicator framework to calculate Outcome.

\section{Table 1: Indicator framework to calculate Outcome}

\begin{tabular}{|c|c|c|}
\hline Outcome & \multicolumn{2}{|r|}{ Indicator Name } \\
\hline \multirow[t]{5}{*}{ 1) } & \multicolumn{2}{|c|}{ Sustainability Indicator } \\
\hline & \\
\hline & b) Social and Demographic Indicator & \\
\hline & \multicolumn{2}{|c|}{ c) Land use Indicator } \\
\hline & d) Tral & ort Indicator \\
\hline \multirow[t]{4}{*}{ 2) } & \multicolumn{2}{|c|}{ Economic Indicator } \\
\hline & a) & Work force participation (slum) \\
\hline & b) & Work force participation (non-slum) \\
\hline & c) & Households with specific assets \\
\hline \multirow[t]{17}{*}{ 3) } & \multicolumn{2}{|c|}{ Social and Demographic Indicator } \\
\hline & a) & Percent of slum population* \\
\hline & b) & Total school \\
\hline & c) & Population literate \\
\hline & d) & Total literate (percentage) \\
\hline & e) & Marginal workers \\
\hline & f) & Percentage of marginal to total workers \\
\hline & g) & Main workers slum (percentage) \\
\hline & h) & Municipal school \\
\hline & i) & Private School \\
\hline & j) & Teachers \\
\hline & k) & Student \\
\hline & l) & Pupil teacher ratio \\
\hline & m) & Male literacy (percentage) \\
\hline & n) & Female literacy (percentage) \\
\hline & o) & Share of population out of total population \\
\hline & p) & Sex Ratio \\
\hline \multirow[t]{12}{*}{ 4) } & \multicolumn{2}{|c|}{ Land Use Indicator } \\
\hline & a) & Residential land use (percentage) \\
\hline & b) & Commercial land use (percentage) \\
\hline & c) & Offices land use (percentage) \\
\hline & d) & Industrial land use (percentage) \\
\hline & e) & Natural area and open spaces land use (percentage) \\
\hline & f) & Education amenities land use (percentage) \\
\hline & g) & Medical amenities land use (percentage) \\
\hline & h) & Social amenities land use (percentage) \\
\hline & i) & Public utilities and facilities land use (percentage) \\
\hline & j) & Transport and communication land use (percentage) \\
\hline & $\mathrm{k})$ & Vacant land use (percentage) \\
\hline \multirow[t]{6}{*}{ 5) } & \multicolumn{2}{|c|}{ Transport Indicator } \\
\hline & Road & \\
\hline & & Connectivity to roads \\
\hline & b) & Road land (percentage) \\
\hline & c) & Connectivity to expressway \\
\hline & Rail & \\
\hline
\end{tabular}




\section{Infrastructure}
a) Railway station (Number)
b) Railway station land (in percentage)
c) Railway yards/siding land (in percentage)
d) Railway terminal land (in percentage)

a)Bus depot

b)Bus depot and bus station land (in percentage)

c) Public parking land (in percentage)

d) Number of train station per area of ward (Number /sq. km)

e) Number of train station per lakh population of ward

f) Connectivity to mass transit (metro phase 1)

g) Connectivity to monorail (line 1)

Finance

a) Expenditure by MCGM in 2010-11 on roads

b) Expenditure by MCGM in 2010-11 on footpaths/pavements/pathways

c) Expenditure by MCGM in 2010-11 on fixing of potholes and spot repairs to road

d) Money spend on roads as percentage of overall expenditure

e) Total expenditure (MCGM) per 1000 population

${ }^{*}$ Note: The value for mentioned indicator we have taken (1-normalize) to represent one as best and zero as worst value. These are negative indicators. For e.g. slum represents non-slum.

\section{Results and discussion}

Greater Mumbai has total 24 wards. Ward A, B, C, D, E,F,G represents Mumbai Island, Ward H, K, P, R represents Western suburbs and Ward L, M , N, S, T represents Eastern suburbs.

\subsection{Sustainability indicator}

The performance of wards in economic, social \& demographic, land-use and transport access indicators in Greater Mumbai is shown in Figure 2, 3, 4 and 5 below.

\section{Economic Indicator}

Figure 2: Economic Indicator value ward wise

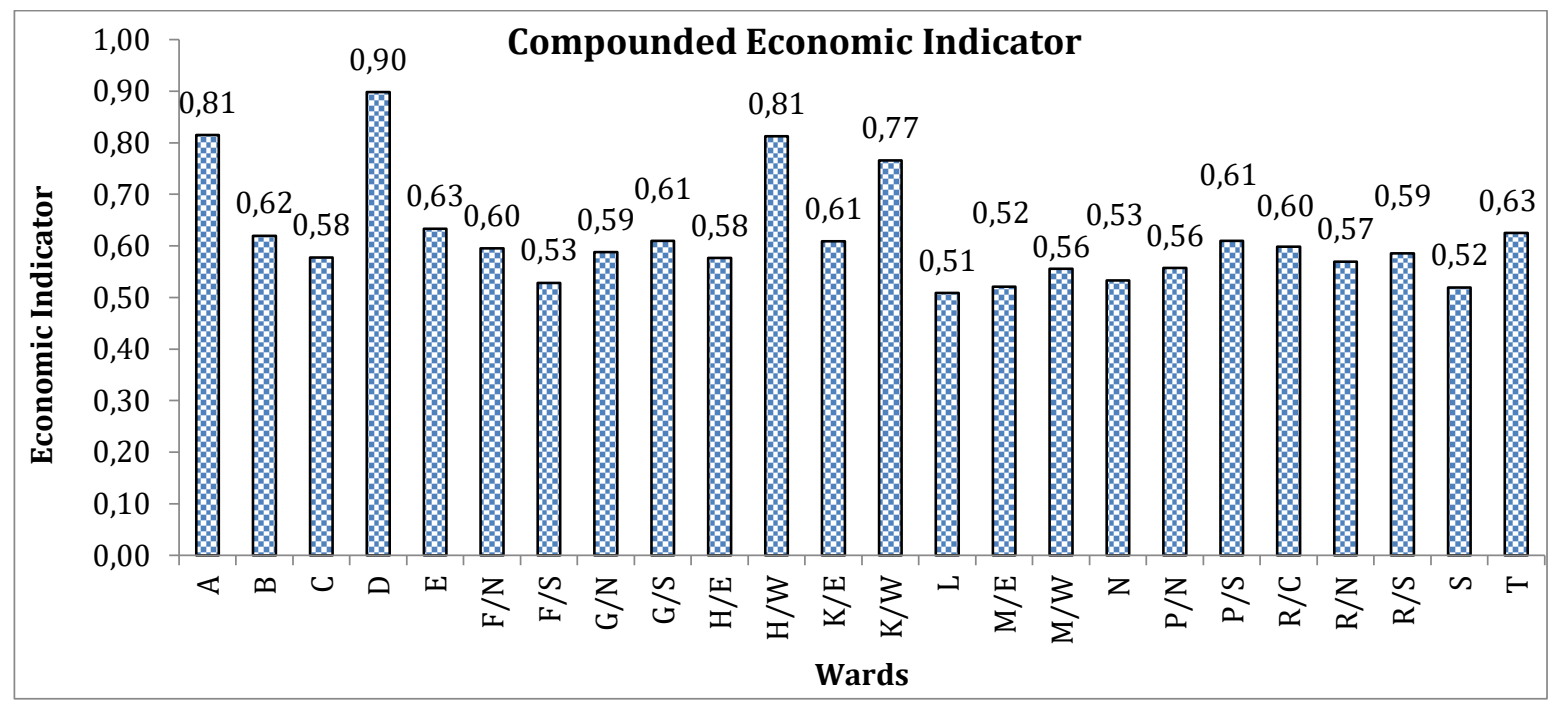

In terms of economic indicator, the best performing wards are D (Grant road), A (Colaba), H/W (Bandra) and K/W(Andheri west) (in island and western suburbs) and wards which are not performing well are wards L (Kurla), S (Bhandup), M/E (Chembur East), F/S (Parel) and N (Ghatkopar) (mostly in eastern suburbs). The top performing wards have high work force participation rate for slums as well as non-slum population and high number of households with assets like cars. These are the drivers for best performance on economic indicator. 


\section{Social and Demographic Indicator}

Figure 3: Social and Demographic Indicator value ward wise

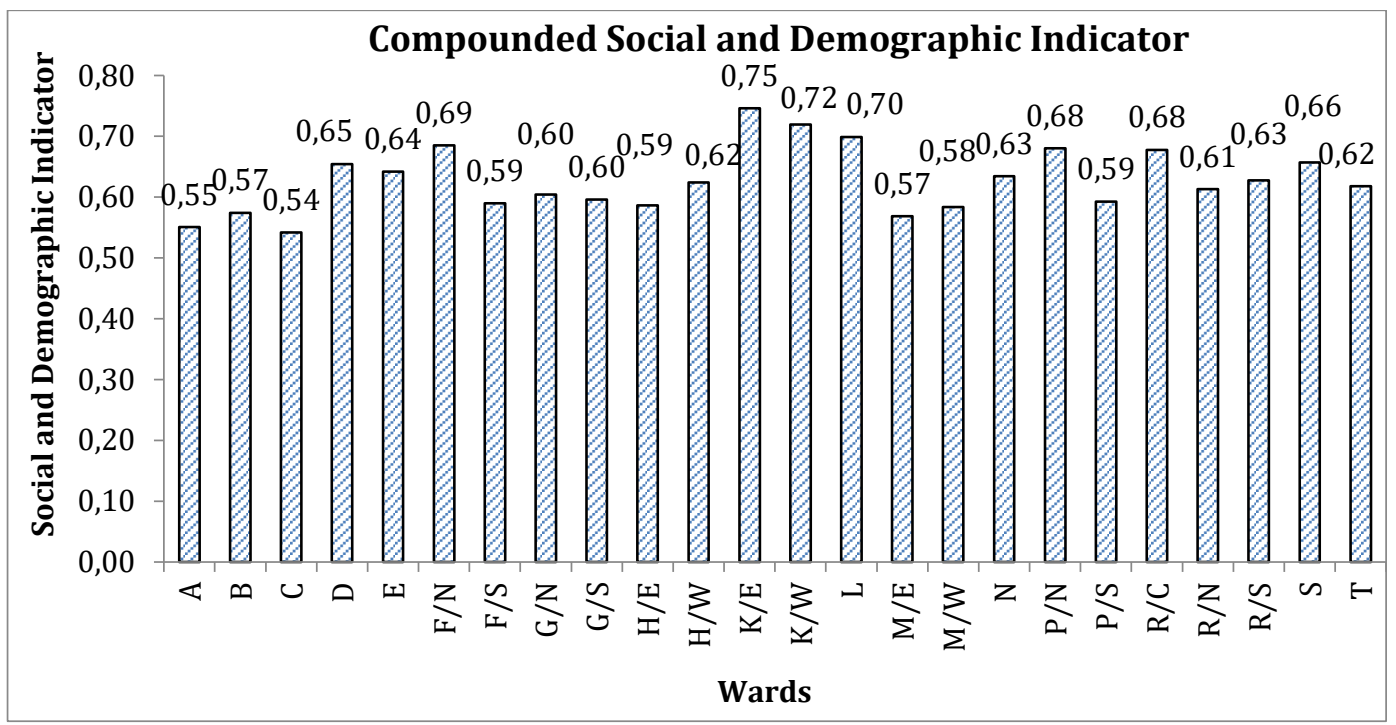

In terms of social and demographic indicator, the best performing wards are K/E (Andheri east), $\mathrm{K} / \mathrm{W}$ (Andheri west), L (Kurla) and F/N (Matunga) and wards which are not performing better are $\mathrm{C}$ (Marine lines), A(Colaba), M/E (Chembur east), B (Sanhurst road) and M/W (Chembur west). Wards C (Marine lines), A (Colaba), B (Sanhurst road), M/E (Chembur east) and M/W (Chembur west) are not performing better in social and demographic indicators. Wards M/E (Chembur east) has lowest performance in terms of economic and social \& demographic indicators and has very high slum population. Literacy is more than average. Health units are very low. These indicators lead to low value of socio-economic indicator. Similarly M/W also have high slum population. Both of these wards fall in eastern suburbs of Mumbai. Ward A (Colaba), B (Sanhurst road) \& C (Marine lines) have low social and demographic indicator due to less school, low population literate, less health units and less municipal schools and so on. These wards fall in island city of Mumbai. The ward A (Colaba) is performing better in economic indicator and performing very low in social and demographic indicator. Ward K/W (Andheri West) is performing better in both economic and social \& demographic indicator. This shows that downtown Mumbai, Colaba performing low compared to suburban areas like Andheri.

\section{Landuse Indicator}

Figure 4: Land Use Indicator value ward wise

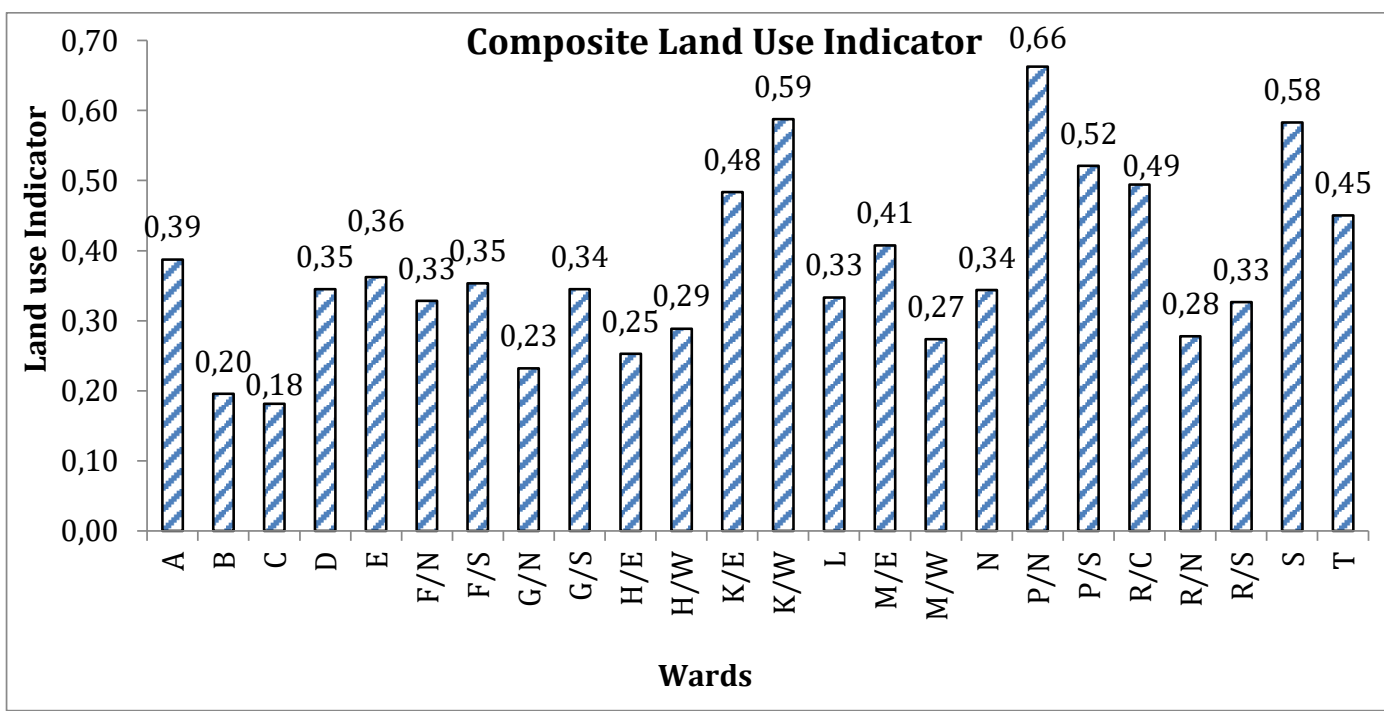


In terms of land use indicator, the better performing wards are $\mathrm{P} / \mathrm{N}$ (Malad), K/W (Andheri west) and $S$ (Bhandup) and the wards which are not performing better are $\mathrm{C}$ (Marine line), B (Sanhurst road), G/N (Dadar/Plaza), H/E (Khar/Santacruz) and M/W (Chembur west). Ward P/N (Malad) is high in terms of residential, commercial, social amenities and transport \& communication land use. Ward K/W (Andheri west) is performing better in terms of economic, social \& demographic and land use indicator. It is highest in terms of social amenities and transport \& communication land use. Wards $\mathrm{C}$ (Marine line), B (Sanhurst road), G/N (Dadar/Plaza), H/E (Khar/Santacruz) and M/W (Chembur west) are found performing low on land use indicators.

\section{Transport Access Indicator}

Figure 5: Transport Access Indicators ward wise

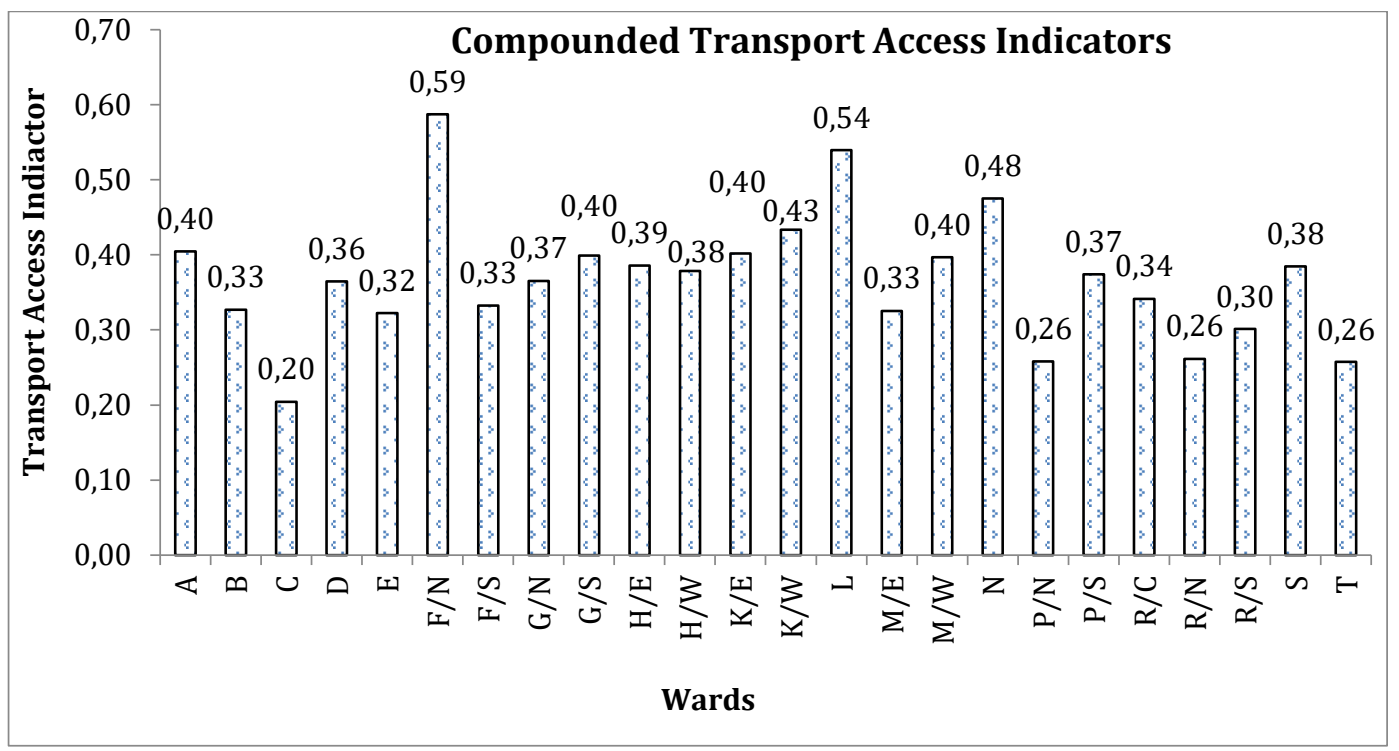

In terms of terms of transport access indicators, the best performing wards are $\mathrm{F} / \mathrm{N}$ (Matunga), $\mathrm{L}$ (Kurla), N (Ghatkopar) and K/W (Andheri west) and the not performing better are C (Marine lines), $\mathrm{T}$ (Mulund), R/N (Dahiser) and $\mathrm{P} / \mathrm{N}$ (Malad). Transport access indicators consist of road, rail, infrastructure and finance indicator related to transport.

$\mathrm{F} / \mathrm{N}$ (Matunga) is better off in terms of social \& demographic and transport access indicator. In social and demographic indicators like schools, total literacy, municipal schools, private schools, teachers, student, male literacy, female literacy and sex ratio are high which leads to high overall indicator value. Ward F/N (Matunga) has better road and infrastructure indicator which leads to high transport indicator value. Connectivity to road is high. Number of railway station is highest. Number of best depot and best depot and bus station land is highest in this ward. This ward has connectivity to Monorail and also expenditure by MCGM on footpaths/pavements/pathways is high. Similarly, ward L (Kurla) is better off in terms of social \& demographic and transport access indicator. Ward K/W (Andheri West) is better in terms of economic, social and demographic, land use indicator and transport indicator. K/W (Andheri west) ward has high work force participation and household assets are high. It has low non-slum population, high population literate, high number of schools, high sex ratio. In terms of land use, it has high residential, commercial, industrial, social \& amenities and transport \& communication land use. It has high connectivity to roads, road land is high, connectivity to metro and transport finance indicators are high. Ward N (Ghatkopar) has high transport access indicator due to high road land, railway terminal land, connectivity to metro, expenditure on footpaths and so on is high.

Ward M/E (Chembur East) in eastern suburbs is worse in terms of economic and social \& demographic indicators. This is mainly due to low assets of households, health units are low, slum population is very high and so on. Ward C (Marine line) is not performing better in terms of social \& demographic, land use and transport access indicators. Ward $\mathrm{C}$ has less schools, health units, municipal schools and private schools and so on. It has low residential, official, education amenities, public utilities and facilities land use and less transport \& communication land use. Similarly, it has less road land, low 
connectivity to expressway, less railway station, no depot, no bus depot \& bus station land, no connectivity to metro and monorail, expenditure on roads, footpaths and so on are low.

The present analysis shows that wards not performing better in terms of transport indicators are $\mathrm{C}$ (Marine lines), $\mathrm{T}$ (Mulund), R/N (Dahiser) and P/N (Malad). Most of them fall in eastern and western suburbs. Shirgaokar, M. (2012) thesis also mentions that the socio-economic and travel indicators showed that commuters to work destinations in the urban periphery were at a disadvantage relative to their central business district (CBD) going colleagues.

\section{Aggregate Sustainability Indicator}

Figure 6: Sustainability Indicator

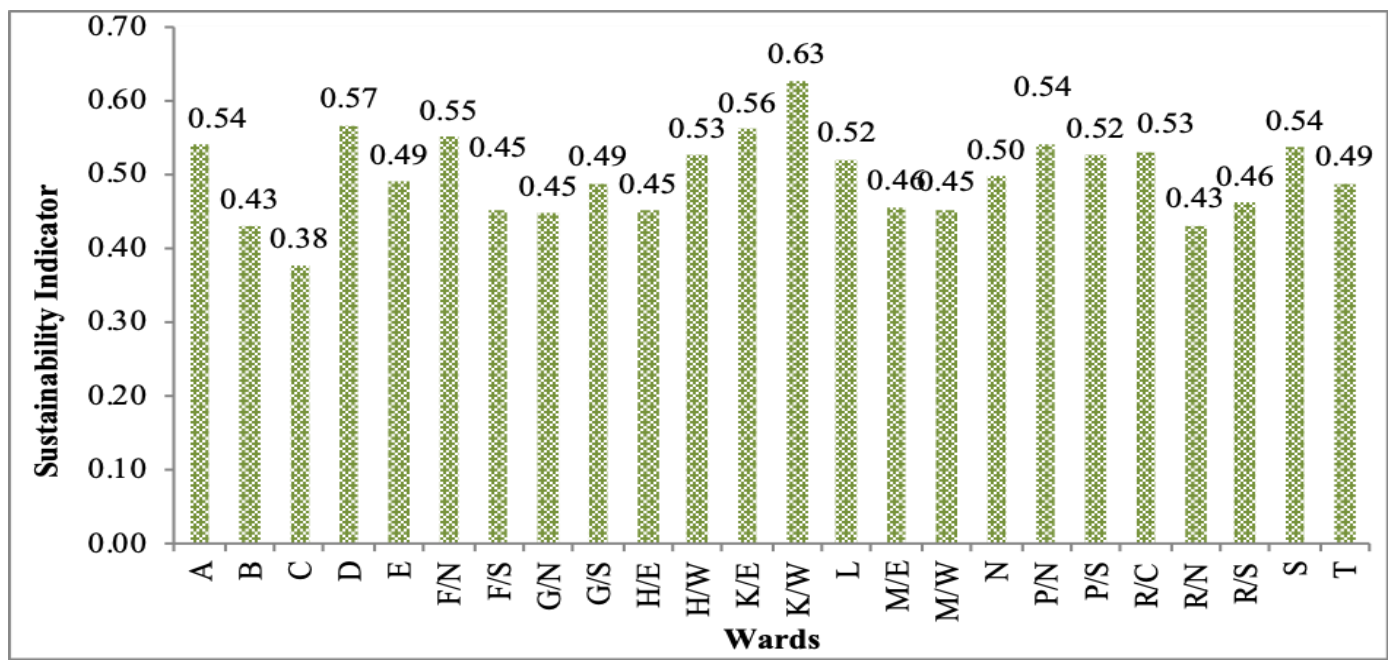

Figure 6 presents the aggregate of all compounded indicators. It is the compounded relative position of wards. Ward K/W (Andheri West) is the best performing wards of all wards in Mumbai. This is due to its better economic, social and demographic, land use indicator and transport indicator. This ward has high work force participation and also household assets are high. It has low non-slum population, literate population is high, high number of schools and high sex ratio. In terms of land use, it has high residential, commercial, industrial, social \& amenities and transport \& communication land use. It has high connectivity to roads, road land is high, connectivity to metro and transport finance indicators are high. Ward D (Grand road) has very high economic indicator and better socio-economic indicator and worse transport access and land use indicator. But has high overall sustainability indicator due to its better economic and socio-economic conditions. This ward has high work force participation and highest household asset. Slum population is low, total literacy is high, male literacy is highest, female literacy is high. It is better in terms of social amenities land use. Connectivity to roads is moderate, best depot are high, expenditure on roads is high.

Ward C (Marine lines) has less schools, health units, municipal schools and private schools and so on. It has low residential, official, education amenities, public utilities and facilities land use and less transport \& communication land use. Similarly, it has less road land, low connectivity to expressway, less railway station, no depot, no bus depot \& bus station land, no connectivity to metro and monorail, expenditure on roads, footpaths and so on are low. Ward C (Marine line) is performing very poorly in terms of social \& demographic, land use and transport access indicators. Similarly ward B (Sanhurst road) has low sustainability indicator due to low value of social \& demographic, land use \& transport indicator. Ward R/N (Dahisar) is performing poorly in terms of sustainable indicator due to low value of land use and transport indicator. Baker in their work (Baker, et al., 2005) mentions that poor in Greater Mumbai spent much larger portions of their incomes on transportation. Shirgaokar mentions in their work (Shirgaokar, M. (2012) that the emergent middle-class is likely to live in housing in the periphery, not necessarily in urban core informal housing. The analysis suggest that though the well-off and working poor live in close proximity, areas with weaker public transit and low employment density tend to have higher percentages of working poor households. The analysis also finds that a large segment of travel in working poor households is for non-discretionary trips. Further the overall low 
sustainability in Greater Mumbai makes it more difficult for urban poor to travel for work, health, education and so on. This needs to be addressed to provide access to all sections of society.

The findings of sustainability shows that wards which are performing better in two or more dimensions are A (Colaba), Ward D (Grand road), K/E (Andheri east) and F/N (Matunga). The ward which is performing best in all dimensions of sustainability is K/W (Andheri west). The wards which are performing low in two or more dimensions are M/E (Chembur east), M/W (Chembur west), C (Marine line), B (Sanhurst road) and R/N (Dahisar). The very poorly performing ward is C (Marine line). The ward $\mathrm{P} / \mathrm{N}$ (Malad) is best in two dimensions socio and demographic and land use but worst in economic and transport dimensions.

\subsection{Sustainability Indicator and HDI}

Sustainability Indicator explains the relative performance of wards on economic, social \& demographic, land use and transport/access criteria. Similarly, HDI also explains relative position of wards on life expectancy, education and income per capita indicators. Human Development index of each ward shows that the overall score is higher when the life expectancy at birth is longer, the education period is longer, and the income per capita is higher. This indicates human development of each ward. It is therefore important to compare the HDI and sustainability indicator for each ward to arrive at sustainability gap. The same is shown in Figure 7.

\section{Figure 7: Sustainability Indicator and HDI}

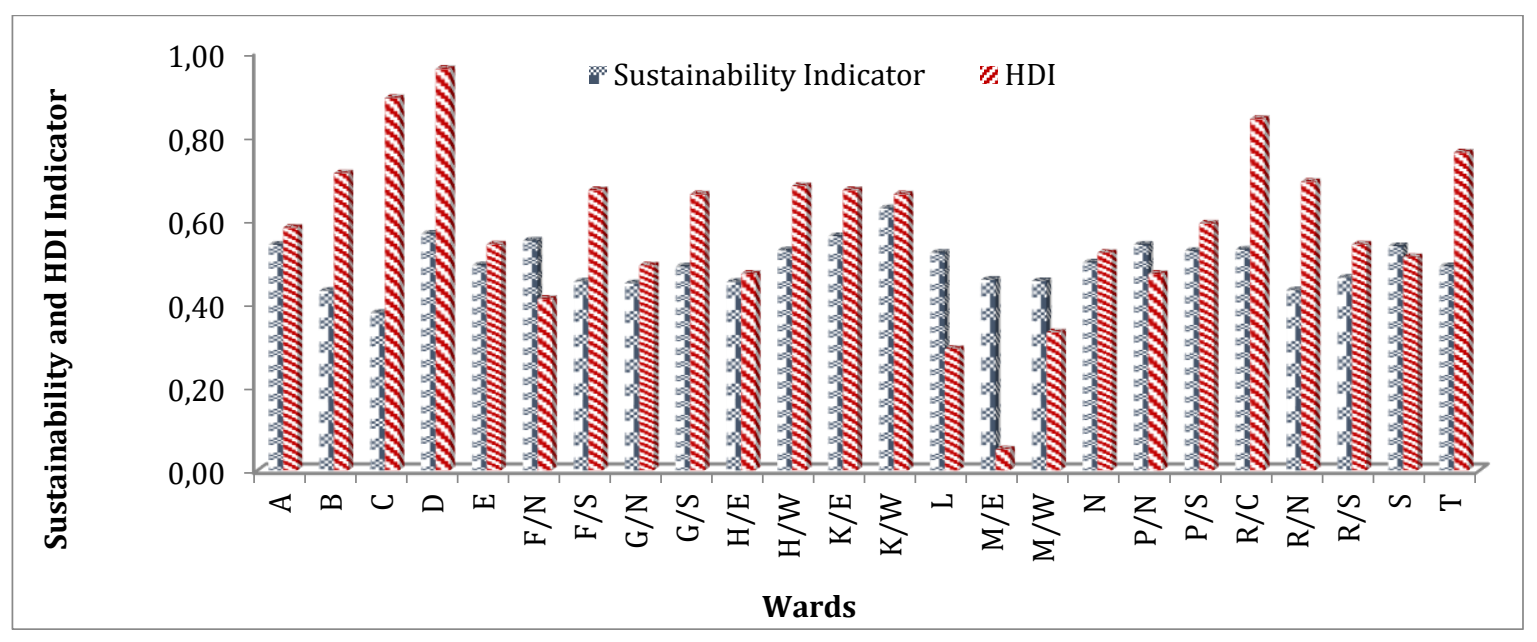

The gap between overall sustainability performance of ward and HDI explains deviations in equitability in service provision. The gap is highest in wards like C (Marine line), D (Grant road), R/C (Borivali west), B (Sanhurst road), T (Mulund) \& R/N (Dahiser). These wards have high HDI but performance of some sustainability indicators is not very high. Ward C (Marine line) is not performing in terms of social \& demographic, land use and transport access indicators and has overall low sustainability. Ward D (Grand road) performed well owning to high economic indicator and better socioeconomic indicator. Its HDI indicator is highest among all wards in Greater Mumbai having a huge gap. Ward R/C (Borivali west) is performing very high in HDI but sustainability is not very high due to lower land use and transport indicator. B (Sanhurst road) has low sustainability indicator due to low value of social \& demographic, land use \& transport indicator. Its performance in HDI indicator is higher. Ward $\mathrm{T}$ (Mulund) has high HDI and lower sustainability indicator due to lower land use and transport indicator. Ward R/N (Dahisar) are poorly performing in terms of overall sustainability indicator due to low value of land use and transport indicator. Its HDI indicator is more than average. The lower performance of sustainability indicator leads to huge gap.

The gap between overall sustainability of wards and HDI is lowest in wards like M/E (Chembur east), L (Kurla), F/N (Matunga), M/W (Chembur West) \& P/N (Malad). These are better performing wards. It is important to note that $\mathrm{M} / \mathrm{E}$ (Chembur east) has lowest HDI among all wards and sustainability is below average. But in comparison to HDI, sustainability indicator is performing better due to better economic, social \& demographic, land use and transport indicators than HDI indicators. 
The extent of sustainability is lower due to better provisions. Similarly, L (Kurla) has low HDI but overall sustainability is above average. Ward M/W (Chembur west) has low HDI and overall sustainability indicator is below average. These wards need more attention and with better services the overall HDI indicator should improve over time. M/E (Chembur east), Ward M/W (Chembur west) and L (Kurla) have very high slum population. Ward F/N (Matunga) has low HDI and sustainability indicator is above average. The household assets are lower and low land use of commercial, offices, natural area, education, public utilities land. Transport indicator is performing above average. Overall transport indicators are best in this ward. The overall sustainability indicator is better than HDI. Ward P/N has low HDI but sustainability is above average. This ward has low household asset, health units, education, medical amenities, public utilities \& facilities land use. The performance of rail transport and overall infrastructure is low. This leads to low transport indicators. It is more important to address those wards where both sustainability and HDI indicator are low. These wards require more attention like M/E (Chembur east), M/W (Chembur west) and L (Kurla). It is important to note that these wards are in western and eastern suburbs of Mumbai and not in island. This shows that in terms of overall sustainability wards in suburbs are worse off than wards in inland Mumbai.

Figure 8: Sustainability Indicator and Transport Access Indicator

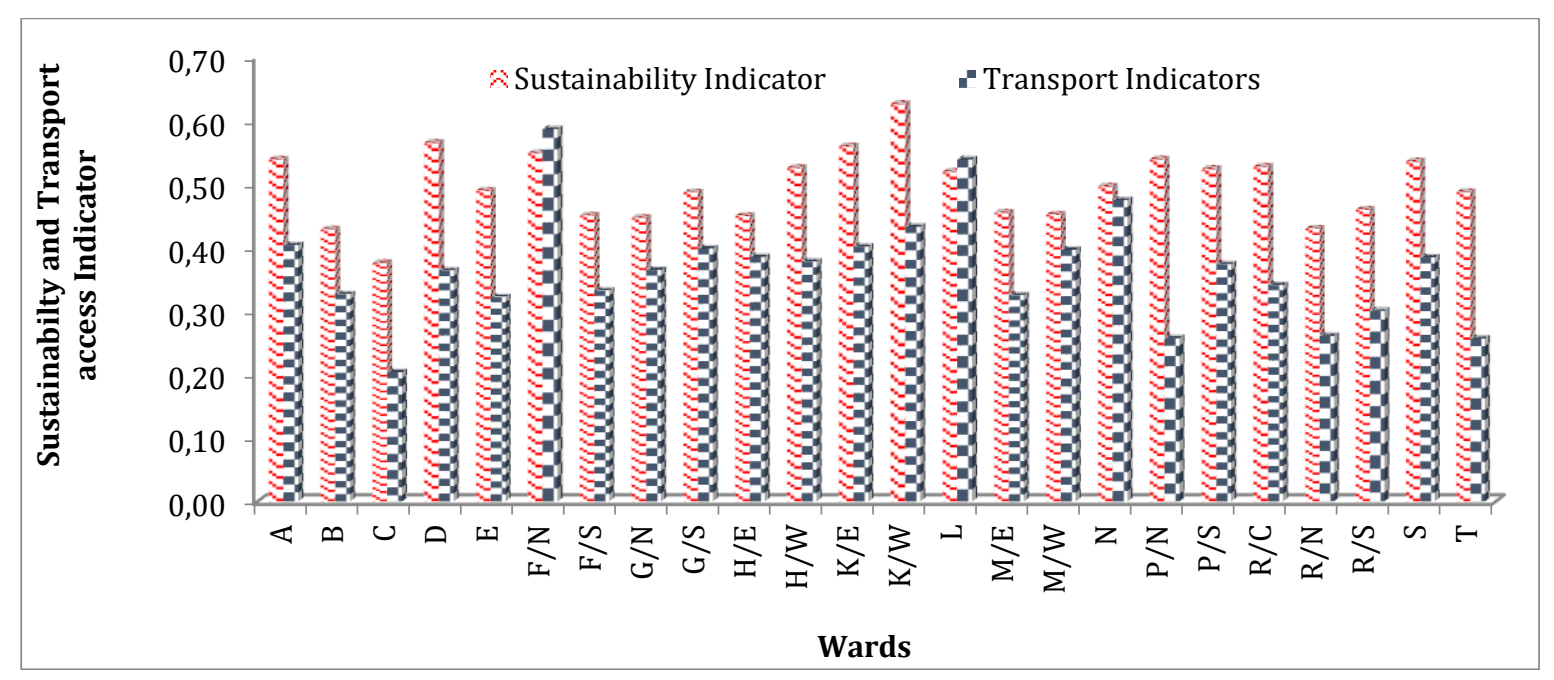

\section{Understanding the relative inequality in Transport service provision}

In terms of transport service provision the gap between overall transport and sustainability indicator is present in most of the wards of Greater Mumbai except ward F/N (Matunga), L (Kurla) and $\mathrm{N}$ (Ghatkopar) as shown in Figure 8. Ward F/N (Matunga) and L (Kurla) are performing better in overall transport indicator. Ward $\mathrm{F} / \mathrm{N}$ has better performance in transport and sustainability. Ward $\mathrm{F} / \mathrm{N}$ (Matunga) sustainability is above average. It has low household asset, offices, education and so on and performing above average on overall transport indicator. The performance in transport indicator is better than sustainability indicator in ward F/N (Matunga) and L (Kurla). Ward L (Kurla) has very high slum population. The gap between overall sustainability and transport is high in wards like $\mathrm{P} / \mathrm{N}$ (Malad), T (Mulund), D (Grant Road), K/W (Andheri west) and R/C (Borivali west). In ward P/N the overall sustainability level is above moderate but the transport indicator is low. In ward $\mathrm{T}$ the overall sustainability is below moderate level and transport indicator is low. Ward D is above moderate level in terms of sustainability indicator but the transport indicator is low. Similarly for Ward K/W and R/C the sustainability indicator is above average but the transport access indicator is low.

It is important to address those wards where both sustainability and transport access is low and these wards are C (Marine line), E (Byculla), M/E (Chembur east), R/N (Dahisar) and T (Mulund). Ward $\mathrm{C}$ (Marine line) is poorly performing in terms of social \& demographic, land use and transport access indicators. Therefore, it has low sustainability and even low performance on overall transport. Similarly, $\mathrm{M} / \mathrm{E}$ (Chembur east) has sustainability indicator below average and slum population. Ward R/N (Dahisar) are poorly performing in terms of overall sustainability indicator due to low value of land use 
and transport indicator. This shows there is urgent need to address provision of transport access in most of the wards of Greater Mumbai.

Measuring the gap between HDI and sustainable performance of the system identifies the gap between economic wellness and overall sustainability of each ward. Comparing their relative performance on overall sustainability with their relative position on transport connectivity brings out the "commuteness" of some of the well performing and some wards under performing in Mumbai. This is nothing but inequity in transport service provision that would help in assessing which wards would need to have augmentation of transport investments.

\section{Conclusion}

This paper has addressed two important aspects of Mumbai city at ward level:

1) Sustainability Indicator explains the relative performance of wards on economic, social \& demographic, land use and transport criteria.

2) The extent of sustainability in various wards of Greater Mumbai was measured by calculating the gap between sustainability \& HDI indicator and sustainability \& transport access indicator

\section{Sustainability Indicators}

The findings of sustainability indicator shows that wards with better overall performance in two or more dimensions are A (Colaba), K/E (Andheri east), L (Kurla) and F/N (Matunga). The ward which is performing best in overall performance of sustainability is $\mathrm{K} / \mathrm{W}$ (Andheri west). The wards which are performing low in two or more dimensions of sustainability are M/E (Chembur east), M/W (Chembur west) and R/N (Dahisar) which falls in suburbs and C (Marine line), B (Sanhurst road) which falls in island. The ward which is performing very low on sustainability in two or more dimension is M/W (Chembur west) which falls in suburbs of Mumbai. Similarly, ward P/N (Malad) is performing poorly in overall sustainability indicator due to low performance in economic and transport dimensions. But this ward is performing better in other two dimensions socio and demographic and land use. The overall analysis shows that most of the wards in suburbs are not performing better in overall sustainability dimension. Further the overall low sustainability in Greater Mumbai makes it more difficult for urban poor in these wards to travel for work, health, education and so on. This needs to be addressed to provide access to all sections of society.

\section{Sustainability Indicator and HDI}

The gap between overall sustainability performance of ward and HDI explains deviations in equitability in service provision. The gap is highest in wards like C (Marine line), D (Grant road), R/C (Borivali west), B (Sanhurst road), T (Mulund) \& R/N (Dahiser). These wards have high HDI but performance of some sustainability indicators is not very high. The gap between overall sustainability of wards and HDI is lowest in wards like M/E (Chembur east), L (Kurla), F/N (Matunga), M/W (Chembur West) \& P/N (Malad). These are better performing wards. It is more important to address those wards where both sustainability and HDI indicator are low. These wards require more attention like M/E (Chembur east), M/W (Chembur west) and L (Kurla). It is important to note that these wards are in western and eastern suburbs of Mumbai and not in island. This shows that in terms of overall sustainability wards in suburbs are poorly performing than wards in inland Mumbai.

\section{Sustainability Indicator and Transport Access}

In terms of transport service provision the gap between overall transport and sustainability indicator is present in most of the wards of Greater Mumbai except ward F/N (Matunga), L (Kurla) and $\mathrm{N}$ (Ghatkopar). Ward F/N (Matunga) and L (Kurla) are performing better in overall transport indicator. It is important to address those wards where both sustainability and transport access are low and these wards are C (Marine line), E (Byculla), M/E (Chembur east), R/N (Dahisar) and T (Mulund). Ward C (Marine line) is poorly performing in terms of social \& demographic, land use and transport access 
indicators. Therefore, it has low sustainability and even low performance on overall transport. Similarly, $\mathrm{M} / \mathrm{E}$ (Chembur east) has sustainability indicator below average and slum population. Ward R/N (Dahisar) are poorly performing in terms of overall sustainability indicator due to low value of land use and transport indicator. This shows there is urgent need to address provision of transport access in most of the wards of Greater Mumbai. This will lead to equitable provision of transport infrastructure and services. The wards M/E (Chembur east), R/N (Dahisar) and T (Mulund) are in suburbs and need better provision of transport infrastructure and services. Ward M/E (Chembur east) has very high slum population which needs to travel for work and other activities.

\section{Citation information}

Juyal, S., \& Yedla, S. (2020). Sustainability of transport system: Case study of Greater Mumbai. Journal of Sustainable Development of Transport and Logistics, 5(2), 153-167. doi:10.14254/jsdtl.2020.52.14

\section{References}

Abhyankar, A. A., Paliwal, M., Patwardhan, A., \& Inamdar, A. B. (2013). Identification of vulnerable area in municipal corporation of Greater Mumbai due to extreme events based on socio-economic indicators. Indian Journal of Geo-Marine Sciences.

Baker, J., Basu, R., Cropper, M., Lall, S., \& Takeuchi, A. (2005). Urban Poverty and Transport: The Case of Mumbai. World Bank Policy Research, Working Paper 3693.

Baker, J. L., \& Denning, W. (2005). Development of a Transport Module for Multi-topic Household Surveys (No. TP-5).

Gannon, C., \& Liv, Z. (1997). Poverty and Transport. World Bank Report (WB).

Lawson, R. A., McMorrow, K., \& Ghosh, B. (2013). Analysis of the non-motorized commuter journeys in major Irish cities. Transport Policy, 179-188.

LEA. (2008). Comprehensive transportation study for Mumbai Metropolitan Region. Technical assistance by the World Bank, MMRDA.

Litman, T., \& Burwell, D. (2006). Issues in sustainable transportation. International Journal of Global Environmental Issues, 6(4), 331-347.

MCGM. (n.d.). Draft Development Plan for Greater Mumbai. Preparatory Studies.

MCGM. Index for the Greater Mumbai City Development Plan (2005 to 2025).

MCGM. (2012). Municipal Corporation of Greater Mumbai Year Book.

de Freitas Miranda, H., \& da Silva, A. N. R. (2012). Benchmarking sustainable urban mobility: The case of Curitiba, Brazil. Transport Policy, 21, 141-151.

Mundu, G. B., \& Bhagat, R. B. (2008). Slum conditions in Mumbai with reference to the access of civic amenities. IIPS Mumbai ENVIS Center, 5(1), 3.

Mumbai Human Development Report. (2009).

Nathan, H. S. K., \& Reddy, B. S. (2013). Urban transport sustainability indicators-application of multiview black-box (MVBB) framework. International journal of environment and sustainable development, 12(3), 285-312.

Nijkamp, P. et. al. (2009). Sustainable Transportation, An International Perspective. MIT Journal of Planning, 9. 
Reddy, S. B., \& Balachandra, P. (2013). Benchmarking urban sustainability-a composite index for Mumbai and Bangalore. IGIDR, Working Paper.

Shirgaokar, M. (2012). The rapid rise of Middle class vehicle ownership in Mumbai. A dissertation submitted in partial satisfaction of the requirements for the degree of Doctor of Philosophy in City and Regional Planning, University of California, Berkeley.

UNEP. (2011). Promoting Low Carbon Transport in India, Macro and City Level Indicators for a Sustainable Transportation System in India. Expert Workshop on Indicators for Sustainable Transport.

UN Habitat. (2013). Planning and Design for sustainable urban mobility: Policy directions. Global report on human settlements 2013, Abridged edition, United Nations Human settlements programme.

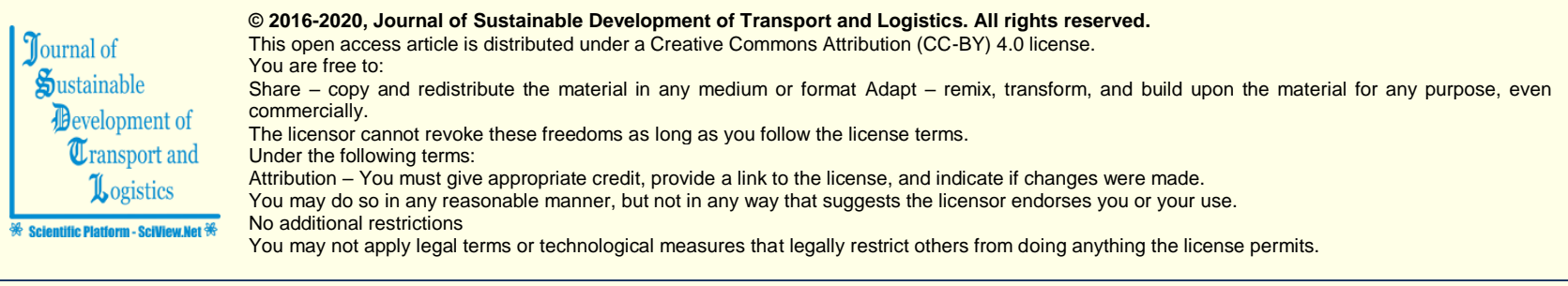

Journal of Sustainable Development of Transport and Logistics (ISSN: 2520-2979) is published by Scientific Publishing House "CSR",

Poland, EU and Scientific Publishing House "SciView", Poland, EU

Publishing with JSDTL ensures:

- Immediate, universal access to your article on publication

- High visibility and discoverability via the JSDTL website

- Rapid publication

- Guaranteed legacy preservation of your article

- Discounts and waivers for authors in developing regions

Submit your manuscript to a JSDTL at https://jsdtl.sciview.net/ or submit.jsdt|@sciview.net 